\title{
TRANSFERRING INFANTS < 32 WEEKS' GESTATION FROM THE DELIVERY ROOM TO THE NICU. HOW VIGILANT ARE WE IN AVOIDING HYPOXIA/HYPEROXIA DURING THE FIRST “GOLDEN HOUR"?
}

\author{
M. Thio ${ }^{1}$, L. Simionato ${ }^{2}$, A. Saraswat ${ }^{2}$, J.A. Dawson ${ }^{1,3}$, P.G. Davis ${ }^{1,2,3}$ \\ ${ }^{I}$ Neonatal Services, The Royal Women's Hospital, ${ }^{2}$ Dept of Obstetrics \& Gynaecology, University of \\ Melbourne, ${ }^{3}$ Murdoch Childrens Research Institute, Melbourne, VIC, Australia
}

Background: Clinicians know about the dangers of hyperoxia and hypoxia in the delivery room and NICU. Less attention is paid to the period of transport and early stabilisation in the NICU. We aimed to investigate the time spent with $\mathrm{SpO}_{2} 85-94 \%$ during the first hour after birth.

Method: A prospective observational study of clinical practice was undertaken. Infants $<32$ weeks gestation were enrolled. A pulse oximeter (PO) sensor was applied to the right hand after birth, remaining connected until 60 minutes after birth. Clinical interventions were recorded during this time and matched with $\mathrm{PO} \mathrm{SpO}_{2}$ data for analysis. Hyperoxic periods were only analysed when $\mathrm{FiO}_{2}>0.21$. Clinicians were unaware of the aims of the study.

Results: 32 infants were studied, mean (SD) birth weight 1101(330)g, gestational age 29(2) weeks. Median(IQR) time spent in the transport cot and NICU were 9(7-11)min and 30(27-33)min respectively, and time babies spent with $\mathrm{SpO}_{2}>94 \%$ if receiving supplemental oxygen was 2.6(1.5-4.6)min and 5.4(2.19.1)min respectively.

\begin{tabular}{|c|c|c|c|c|}
\hline $\mathbf{F i O}_{2}>\mathbf{0 . 2 1}$ & $\mathrm{SpO}_{2} \mathbf{8 5 - 9 4 \%}$ & $\mathbf{S p O}_{2}>\mathbf{9 4 \%}$ & $\begin{array}{c}\mathrm{SpO}_{2}>94 \% \text { in } \\
\text { babies on CPAP }\end{array}$ & $\begin{array}{c}\mathrm{SpO}_{2}>94 \% \text { in } \\
\text { intubated babies }\end{array}$ \\
\hline \hline Transport & $37(12-67) \%$ & $45(8-67) \%$ & $60(16-67) \% \mathrm{n}=21$ & $18(2-76) \% \mathrm{n}=9$ \\
\hline \hline NICU & $46(29-68) \%$ & $44(18-62) \%$ & $50(19-66) \% \mathrm{n}=22$ & $28(9-46) \% \mathrm{n}=9$ \\
\hline
\end{tabular}

[Proportion of time an $\mathrm{SpO} 2$ ranges, median(IQR)]

The proportion of time with $\mathrm{SpO}_{2}>94 \%$ during Transport and NICU was similar. Babies managed with CPAP compared to intubated infants had a greater proportion of time with $\mathrm{SpO}_{2}>94 \%$ in transport and the NICU setting.

Conclusions: $\mathrm{SpO}_{2}$ measurements often fell outside the target range during the early postnatal period. Clinicians tolerate saturations higher than the "safe" range during the first hour after birth. 